\title{
UN NOMBRE EN LA TORRE DE MARFIL. PSICOANÁLISIS Y PSICOLOGÍA PROFUNDA A TRAVÉS DE LA HISTORIA INTERMINABLE DE M. ENDE (1979)
}

\author{
Miguel Huertas Maestro \\ Instituto de Historia, Centro de Ciencias Humanas y Sociales, CSIC. \\ Email: mhmaestro@gmail.com \\ ORCID iD: https://orcid.org/0000-0002-8513-2293
}

Recibido: 3 noviembre 2020; Aceptado: 26 enero 2021

Cómo citar este artículo/Citation: Huertas Maestro, Miguel (2021) “Un nombre en la torre de marfil. Psicoanálisis y psicología profunda a través de La historia interminable de M. Ende (1979)", Asclepio, 73 (2): p566. https://doi.org/10.3989/asclepio.2021.24

RESUMEN: El objetivo del artículo es abordar la relación entre psicoanálisis y arte -en este caso, literatura- entendiendo que este último arrastra intuiciones que posterior o paralelamente hipotetizadas por las disciplinas psi. Para ello, se parte del concepto de "arte visionario" de Carl Gustav Jung y de la noción de que el "artista precede" de Jacques Lacan para explorar la manera en la que una obra como La Historia Interminable (M. Ende) permite arrojar luz sobre los desarrollos teóricos de estos dos autores. En el caso de J. Lacan, los registros de lo simbólico, lo imaginario y lo real. En el caso de C. G. Jung, el viaje interior que supone el proceso de individuación y el contacto con arquetipos del inconsciente colectivo.

PALABRAS CLAVE: Psicoanálisis; Arte; Psicología Profunda; Proceso de Individuación.

\section{A NAME IN THE IVORY TOWER. PSYCHOANALYSIS AND DEPTH PSYCHOLOGY THROUGH MICHAEL ENDE'S THE NEVERENDING STORY}

ABSTRACT: The aim of this paper is to address the relation between psychoanalysis and literary art. We assume that art presents intuitions latter developed by PSI theories. On the basis of Visionary Art (Carl Gustav Jung) and "the artist always precedes" (Jacques Lacan) concepts, we explore the way in which The Neverending Story (M. Ende) sheds light on the theories developed by these authors. On one hand, the J. Lacan's concepts of the Imaginary, the Symbolic and the Real. On the other hand, the inner path of the Individuation Process and the archetypes of the Collective Unconscious of C.G. Jung.

KEY WORDS: Psychoanalysis; Art; Deep Psychology; Individuation Process.

Copyright: ( 2021 CSIC. Este es un artículo de acceso abierto distribuido bajo los términos de la licencia de uso y distribución Creative Commons Reconocimiento 4.0 Internacional (CC BY 4.0) 


\section{INTRODUCCIÓN}

La Historia Interminable es una conocida obra de literatura de fantasía salida de la pluma de escritor alemán Michael Ende en 1979, siendo objeto de atención académica en numerosas ocasiones (Hocke y Kraft, 1997; Boccarius, 1990). Para el caso que nos ocupa el lazo entre esta obra literaria y el psicoanálisis- encontramos que una de las ópticas predominantes es la visión de la obra a partir de la lente del inconsciente colectivo jungiano y el Monomito conceptualizada por Joseph Campbell (2013), en especial aquello que tiene que ver con la estructura del rito iniciático (Jiménez, 2013). Esto no es una novedad en el género, ya que la literatura fantástica bebe y revive al tiempo las fuentes míticas de la humanidad en una época en la que éstas ya no son "el lenguaje religioso de nuestro tiempo" (Hillman, 2004, p. 20); no en vano una de las obras de fantasía más conocidas en la actualidad, El Hobbit (Tolkien, 2002), lleva por subtítulo Historia de una ida y una vuelta, frase que podría servir de síntesis al Monomito campbelliano.

El objetivo del presente trabajo, emparentado pero diferente a lo mencionado con anterioridad, es la búsqueda de la relación entre psicoanálisis y arte, entendiendo que el valor de dicho lazo no está en elaborar la psicobiografía del autor o pretender analizar su psique individual a través de su obra sino, por el contrario, entender que las intuiciones plasmadas en las obras de arte -literarias, en este caso- arrastran, simbólicamente, valiosas intuiciones sobre la mente humana que son posterior o paralelamente sistematizadas teóricamente por las hipótesis de la psicología o el psicoanálisis.

Esto es, a grandes rasgos, lo que Carl Gustav Jung denominó arte visionario (Montiel, 2012, p. 11), y que compone el primer eje rector del que partiremos: la hipótesis de que en las páginas de La Historia Interminable se halla, de forma latente, la larga búsqueda del alma del proceso de individuación jungiano y su relación con los arquetipos de su inconsciente colectivo.

El segundo eje, que parte de presupuestos psicoanalíticos diferentes, es la concepción del autor como pionero que ha sido propuesta desde la óptica estructuralista del psicoanálisis encabezada por Jacques Lacan (1988, p. 66) al afirmar, recogiendo a Freud, que "el artista precede", implicando así que las obras artísticas son susceptibles de arrojar luz sobre las dinámicas ocultas de la vida psíquica (Regnault, 1995). En ese sentido comprobaremos cómo el viaje de ida y vuelta que nos propone Ende tiene mucho que ver con el mundo simbólico-imaginario, y el horror del vacío que supone la dimensión de lo Real.

En ambas propuestas encontramos la esencia de este trabajo, que no pretende ser psicoanálisis aplicado sino, por el contrario, mostrar las posibilidades del "arte aplicado al psicoanálisis". Se toma el término de la propuesta de Blanca Sánchez cuando, abordando la relación entre arte y psicoanálisis en Lacan, indica:

El desafío permanente de Lacan de tratar de invertir la perspectiva freudiana del psicoanálisis aplicado al arte, nos permite deducir que hay en él un intento de construir (...) un modo de leer que permita sostener la idea del arte aplicado al psicoanálisis (Sánchez, 2015, p. 124).

Partiremos, además, de la noción de que "la teoría psicoanalítica es una tentativa de hacer comprensible dos hechos -la transferencia y la resistencia-, que surgen de un modo singular e inesperado al intentar referir los síntomas patológicos de un neurótico a sus fuentes en la vida del mismo. Toda investigación que reconozca estos dos hechos y los tome como punto de partida de su labor podrá ser denominada como psicoanálisis, aun cuando llegue a resultados distintos a los míos" (Freud, 1973, p.1900). En este sentido, y pese a distinguir las notables diferencias entre las teorías lacanianas y la psicología profunda jungiana, ambas se consideran aquí partes del rico marco teórico del psicoanálisis.

La Historia Interminable es, en el contexto de este trabajo, un relato sobre la narrativa personal de la subjetividad humana y los símbolos y figuras que la componen. Algunos de ellos guardan relación con apariciones de personajes o conceptos similares que son recurrentes en las narraciones y mitos de nuestra cultura -el mentor, el enemigo, el niño eterno-, desde las más fundantes hasta las más contemporáneas.

Una perspectiva de las dos que se presentan en este trabajo, la de la psicología arquetípica, señala que el núcleo común de dichas figuras simbólicas no es sino el contenido del inconsciente colectivo, estructura psíquica común a toda la humanidad sobre la que se sistematiza nuestro inconsciente personal. Para Jung, un arquetipo sería "un centro innato (...) con la capacidad para iniciar, influir y mediar en las características del comportamiento y la experiencia de los seres humanos, con independencia de su raza, cultura, época histórica o localización geográfica" (Stevens, 1993, p. 40), siendo la influencia de los factores personales y socioculturales lo que formarían los complejos del inconsciente personal jungiano. Estos arquetipos colectivos, es decir, comunes a todos los seres humanos, son expresados simbólicamente a través de las religiones y las narraciones, con las variaciones propias de las épocas históricas determinadas. Podría ser interesante indicar también que el concepto de inconsciente colectivo podría definirse también como el correlato psíquico de la predisposición genética de la especie a contar con determinado número de miembros. 
La Historia Interminable se trata de una novela particular, que narra las vivencias de unos personajes determinados, escrita por un hombre en concreto, y en cierto contexto histórico, pero tiene algo de común. Como Bastián -el protagonista de la novela- al abrir el libro, y más tarde "vivirlo", las personas también existimos en un mundo que es inexplicable por sí mismo, en una realidad -con aspectos internos y externos- que ama esconderse. A fin de cuentas, "En rigor nada tiene significado, pues cuando no existía ningún hombre pensante no había nadie que interpretara los fenómenos. Sólo tiene significado lo no comprensible. El hombre ha despertado en un mundo que no comprende y trata de interpretarlo" (Jung, 1970, p. 55). El viaje de Bastián sólo es un correlato del viaje que las personas tenemos oportunidad de emprender si queremos sacar la luz aquello que nos mueve: el proceso de individuación. Así, entendemos que "En esta perspectiva el autor y su obra se muestran a la vez como síntoma de una enfermedad de la cultura y como ejemplo de un singular proceso de curación" (Montiel, 2012, p. 12).

\section{LO SIMBÓLICO Y LO IMAGINARIO FRENTE A LA NADA}

La Historia Interminable también nos muestra, de un modo diferente al sistematizado por el estructuralismo y por las propuestas lacanianas, la importancia de la trama simbólico-imaginaria para proteger la vida anímica del abismo devorador de lo Real.

La novela es un relato de fantasía que nos narra el viaje de un niño al interior del mundo imaginario del libro que lee y cómo esto supone para él un "rito de paso", y comparte con el psicoanálisis algunos elementos clave. El primero de ellos es la idea de que la fuerza motriz de los individuos está más allá de la lógica de su consciencia y que, por fuerza, "seguimos siendo unos extraños para nosotros mismos" (Nieztsche, 1970, p.877). El segundo, la importancia del lenguaje y del poder de los nombres que damos a las cosas, pero aún más, la importancia de lo que está más allá del lenguaje y la dimensión aterradora de lo que no podemos nombrar y las consecuencias que tiene este proceso fallido.

Nuestra primera reacción, habida cuenta del título y su contenido manifiesto, podría ser pensar que es la dimensión imaginaria la que tiene un peso crucial en el libro que nos ocupa. Sin embargo, muy pronto nos queda claro que la luz que arroja la narración tiene su foco puesto sobre el orden simbólico como eje central de su dinámica, y que es esta dimensión la fuerza de cohesión de los elementos que componen nuestro mundo ante la fuerza negativa que pretende devorarlo.

Una temprana indicación de esto la podemos encontrar en el principio mismo del libro:
Imagen 1. Extracto de la novela.

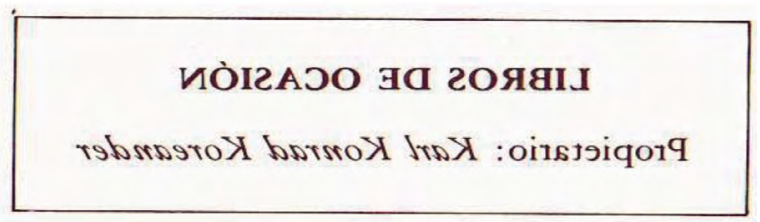

Poco después descubrimos que es el letrero de la tienda de libros de Koreander, el cual, visto desde fuera, adopta un aspecto radicalmente diferente, ya que resulta imposible de comprender en un primer momento. Se trata de un primer atisbo de la importancia que tendrán la multiplicidad de ópticas y las relaciones que las atan. A fin de cuentas, lo único que nos permite entender el mensaje y no caer en la confusión es la operación de girar las letras: darles la vuelta mentalmente para que sean legibles, una ficción imaginaria que nos habla de que "no importa" si lo leemos del revés, pues es el mismo cartel. Sin embargo, ¿podemos encontrar diferencia mayor entre la que existe entre estar a un lado o al otro de una puerta? Quizá la que hay entre el cero y el uno, o entre un sí y un no.

Nuestro protagonista, Bastián Baltasar Bux, aún ignorante de estos mecanismos, acude a la librería de Koreander huyendo tanto de los matones de su colegio como de la frialdad de su padre. En un impulso, totalmente inexplicable para él, roba uno de los libros del anciano y huye a leerlo al desván de su colegio, haciendo novillos en lugar de ir a las clases.

Se nos dice que este comportamiento es extraño en un niño tímido y dócil como Bastián, pero pronto encontramos que, aparte del acoso que sufre en el colegio, el fallecimiento de su madre y la actitud distante y fría de su padre hacen de su casa un lugar tanto o más hostil que el primero. No se trata tanto de un acto de valentía como la temeridad que envuelve la huida:

De todas formas, le daba miedo el colegio, escenario de los fracasos diarios; le daban miedo los profesores, que le reñían amablemente o descargaban sobre él sus iras; miedo los otros niños que se reían de él (...) (Ende, 1989, p. 14).

Es entonces cuando Bastián abre el libro, la puerta al mundo de Fantasía que poco a poco le irá llamando hasta hacerle desaparecer, literalmente, entre sus páginas. Una puerta, podríamos decir, hacia lo imaginario, tan necesaria para Bastián ante la crudeza de su día a día:

"Me gustaría saber", se dijo, "qué pasa realmente en un libro cuando está cerrado. Naturalmente, dentro sólo hay letras impresas sobre el papel, pero sin embargo... Algo debe pasar, porque cuando lo abro aparece de pronto una historia entera (Ende, 1989, p. 17). 
Es entonces cuando descubrimos que, tras la puerta hacia lo imaginario, la tinta de los caracteres de $L a$ Historia Interminable -la "nuestra", el libro que leemos- pasa del rojo oscuro al verde. Es esta diferencia de colores lo que separa el mundo de Bastián -que nosotros leemos- del mundo fantástico del libro que ha robado. Un señalamiento de que sólo los resortes simbólicos, los de la relación y la diferencia, son necesarios para apuntalar el reino de lo imaginario y de que es éste el pacto que lo hace durar. Como veremos, es esta dialéctica simbólico-imaginaria la red que mantiene la cohesión de la propia novela.

\section{Imagen 2. Diferencia de colores en la edición española.}

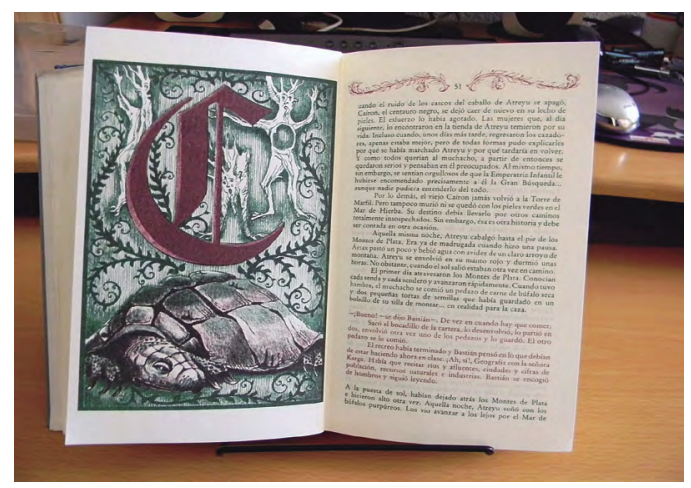

La importancia de que esta trama exista, o más bien, de que deje de existir, la encontramos un poco más adelante, inmersos ya en la historia del libro que está leyendo Bastián. Fantasía es un reino imaginario, poblado por toda clase de criaturas legendarias y cuyo centro es la Torre de Marfil, aunque quizá lo realmente relevante en ese punto es que Fantasía no tiene fronteras: "En el reino sin fronteras de Fantasía no había nadie de quien tuviera que guardarse" (Ende, 1989, p. 28). La primera criatura que nos encontramos en la lectura, un "fuego fatuo infatuado", nos avisa también de las operaciones de la dimensión imaginaria: "No era un hombrecito ni una mujercita, pues esas diferencias no existen entre los fuegos fatuos" (Ende, 1989, p. 21).

Con esto entendemos que el mundo de Fantasía está regido por la operación de lo imaginario, la identidad sin diferencia, la continuidad sin límite. Pero, como ya hemos podido ver, está enmarcado necesariamente por los límites diferenciales de lo simbólico.

Junto a Bastián, con sus ojos, desde su posición, vamos leyendo las primeras líneas y descubrimos que diversos emisarios están acudiendo a la Torre de Marfil con el mismo mensaje desde todo el territorio de ese mundo sin fin. Porque Fantasía se está muriendo:

Es difícil describirlo (...) todo empezó porque, un día el lago de Cálidocaldo ya no estaba allí... Simplemente había desaparecido (...) Donde estaba el lago ya no hay nada... Simplemente nada, ¿comprendéis? (...) No, tampoco es un agujero, un agujero es algo. Y allí no hay nada (Ende, 1989, p. 25)

Algo está fracasando horriblemente en Fantasía, y lo Real, en su nada aterradora, está comenzando a devorarlo todo. El apuntalamiento ha cedido, dejando de sostener lo imaginario y sabemos las consecuencias que esto está teniendo; la lógica del espejo (Lacan, 1986), la dirección de la mirada, se muere: "Como si uno se quedara ciego al mirar ese lugar" (Ende, 1989, p. 25).

Igual que se muere la Emperatriz Infantil, la Señora de los Deseos, la soberana que no gobierna, eterna pero siempre niña, que es el núcleo imaginario que sostiene toda la Fantasía:

Para ella, todos eran iguales. Sólo estaba allí, pero estaba allí de una forma especial: era el centro de toda la vida de Fantasía. Y todas las criaturas, buenas o malas, hermosas o feas, divertidas o serias, necias o sabias, todas, estaban allí sólo porque ella existía. Sin ella no podía subsistir nada, lo mismo que no puede subsistir un cuerpo humano sin corazón (p. 35).

Se nos presenta una imagen poderosa de dicha criatura. Sabemos que no distingue entre "bueno o malo", sabemos que gobierna sin órdenes, sabemos que es una niña pero que nunca envejece, es decir, que no se desgasta y ninguna descarga la erosiona. También sabemos que vive en una Torre de Marfil, en el centro mismo de Fantasía, y que su enfermedad está matando su mundo: la Emperatriz guarda poderosas semejanzas con lo reprimido tal y como lo encontramos descrito en los textos psicoanalíticos (Laplanche y Pontalis, 2016, p. 388).

Sin embargo, el viaje del protagonista del libro que lee Bastián, quien a su vez es el protagonista del libro que nosotros leemos, le llevará a la misma conclusión que componen las tesis dinámicas descubiertas en los albores del siglo XX -y que ya tenían poderosos precedentes, definidos por otras vías- al hallar "la cura por la palabra" (Laín Entralgo, 2005).

"No obstante, sin nombre no puede vivir" (Ende, 1989, p. 61). La Emperatriz Infantil permanece innominada, y es ésa la herida que hace agonizar toda Fantasía, la grieta cada vez más amplia por la que se cuela la marea sin reflejo de lo Real, la Nada que todo lo devora hasta que parece que el que contempla el efecto de su disolución se ha quedado ciego. Tras esta falla, como pudiese verse en la actitud de la Vieja Morla, se arrastra la disolución del signo, el horror al vacío, y la sombra de la pulsión de muerte:

Todo se repite eternamente (...) el mundo está vacío y no tiene sentido. Todo se mueve en círculos. Nada es verdad. Nada es importante (...) ¿ por qué no hemos de 
morir tú, yo, la Emperatriz Infantil, todos? Todo es una apariencia, un juego de la Nada (Ende, 1989, p. 60).

No parece haber esperanza puesto que, pese a ya conocer el remedio, éste no puede alcanzarse: ninguno de los seres de Fantasía, incluido el protagonista que nuestro protagonista lee, puede darle un nombre a la Emperatriz. Porque no hay solución desde lo imaginario, ya que es el reino de la ilusión; necesario, pero no suficiente. Se necesita algo más para hacerlo durar, de un modo similar a lo que ocurre con la Emperatriz Infantil. Un nombre, el paradigma de lo simbólico.

Y eso sólo puede ser introducido desde fuera, desde el entramado de significantes que proyectan la misma sombra de lo Real, esa que amenaza con devorarlo todo (Lacan, 1990).

Pese a la insuficiencia inexorable de lo simbólico-imaginario -que no es sin fracaso-, ante esa Nada, también se constata que es la única herramienta que tenemos para mantenerla a raya, para darle coherencia y significado a un mundo que carece de él, en el intento siempre renovado de convertir la inundación en una simple fuga de agua: nombres y más nombres para nuestra Emperatriz. Porque hay alguien que sí puede nombrarla: "Sólo él, Bastián, podía intervenir. Y tenía que hacerlo si no quería permanecer encerrado también en aquel círculo". (Ende, 1989, p. 183).

Fantasía ha sido prácticamente devorada por la Nada: "Un grano de arena (...). Es todo lo que queda de mi reino sin fronteras (...)". (Ende, 1989, p. 191). Sin embargo, el nombre dado por Bastián a la Emperatriz Infantil es el clavo simbólico que ha podido mantener la estructura en el último momento. $Y$ es esto lo que brinda la posibilidad de mantener viva la subjetividad mediante las complejas dinámicas del deseo: “Fantasía renacerá de nuevo de tus deseos, Bastián, que se harán realidad a través de mí" (Ende, 1989, p. 188).

A fin de cuentas, para Bastián y su Fantasía, al igual que para los demás, la directriz sigue siendo la misma: "No cejar en cuanto al deseo" (Marinas, 2004, p. 134).

\section{LOSARQUETIPOSYELPROCESODEINDIVIDUACIÓN}

Para Carl Gustav Jung, el inconsciente personal se estructura sobre un estrato más profundo de la psique que no correspondería ya a las adquisiciones de la experiencia personal, sino que sería innato e idéntico a sí mismo para todas las personas (Jung, 1970, p. 10): el inconsciente colectivo.

Otras explicaciones útiles comparan esta forma innata de estructuración de la psique a la tendencia general de los seres humanos a contar con un determinado número de brazos y piernas (Montiel, 1997). Jung nos explica: “(...) tenemos que partir de la hipótesis de que el hombre no es una excepción entre las criaturas, en tanto, quiérase o no, posee como todo animal una psique preformada" (1970, p. 72).

Los contenidos del inconsciente colectivo son los arquetipos y éstos hacen su aparición de forma indirecta en mitos y leyendas (Jung, 1970, p. 11). Es importante tener en cuenta que, al tratarse de contenidos inconscientes, su paso al reino de lo consciente les impone un cambio de acuerdo a la psique individual en la que surgen y a las circunstancias que han determinado su desarrollo. En ese sentido, no sería posible encontrar de forma manifiesta arquetipos puros, sino únicamente derivados de los mismos, identificados como representaciones arquetípicas (Jung, 1970, p. 11), del mismo modo que encontramos "retoños" del inconsciente en la teoría freudiana (Laplanche y Pontalis, 2016, p. 118).

Como no es posible conocer de forma directa las predisposiciones psíquicas de los seres humanos, según un criterio funcional éstas deben ser nombradas como "imágenes primordiales" cuyo origen sería posible rastrear desde la rama del individuo hasta el tronco de la especie (Jung, 1970, p. 72). Es, entonces, "la forma específicamente humana de sus actividades" mentales más primitivas. Y es, precisamente, en la fantasía creadora, donde existe más facilidad para que se hagan visibles las mencionadas imágenes primordiales y donde encuentra su sentido el concepto de arquetipo.

Cabe recordar para nuestro trabajo la advertencia (Jung, 1970, p. 73), de que las emergencias arquetípicas no están en ningún caso limitadas en su contenido sino -y de forma parcial- en su forma. Es decir, el arquetipo es un elemento vacío que posibilita la forma de la representación.

A modo de ejemplo, podemos indicar algunas posibles representaciones del arquetipo de la Madre, que puede abarcar desde la madre y la abuela personales hasta las diosas-madre como Deméter o la Virgen del cristianismo como "madre universal", pasando por representaciones más amplias como la patria, la universidad, o la Iglesia (Franz, 1995, p. 74).

Como ya ha sido mencionado, nuestra hipótesis de trabajo sostiene que a través de La Historia Interminable se nos presenta el viaje de un niño hacia el contacto con los arquetipos y la búsqueda de una respuesta que engloba todo su mundo, es decir, el proceso de individuación, por el cual la persona conecta de forma consciente con elementos de su psique ocultos, negados, inconscientes, hasta poder integrarlos al fin en sí misma. De este modo, "la realización de la unicidad del hombre individual es la meta del proceso de individuación" (Franz, 1995, p. 162). La búsqueda consciente del "sí mismo" (Selbst), el eje rector y guía inconsciente que engloba la totalidad de la psique del individuo, y que comúnmente se halla coartado o limitado por cri- 
terios utilitarios de la consciencia, es el fin del largo viaje hacia la individuación.

Y es precisamente un viaje de similares características el que emprende Atreyu, protagonista del libro que lee Bastián -que es, a su vez, el protagonista del libro que leemos-: un viaje para encontrar la cura que sane a la Emperatriz Infantil, el alma del mundo sin fronteras de Fantasía: "Ella te envía a lo desconocido a buscar algo que nadie conoce. Nadie puede ayudarte, nadie puede darte consejos y nadie puede predecir lo que te aguarda" (Ende, 1989, p. 43).

En el camino hacia el centro del sí mismo y, en general, hacia el autodescubrimiento de lo oculto en nuestra psique, caben pocos consejos y ninguna predicción: es el más personal de los caminos, uno que no existe antes de comenzar a recorrerlo, pues verdaderamente se hace al andar. Las pocas recomendaciones que le son dadas a Atreyu presentan, además, poderosos paralelismos con respecto a la búsqueda de uno mismo y su correlato de "unicidad" e integración psíquica: "Por eso debes ir sin armas. Debes dejar que ocurra lo que tenga que ocurrir. Todo debe ser igual para ti: mal y bien, belleza y fealdad, necedad y sabiduría, igual que para la Emperatriz Infantil. Sólo debes buscar y preguntar, pero nunca juzgar por ti mismo" (Ende, 1989, p. 44).

No cuesta mucho detectar el parecido entre estas directrices y la regla de la asociación libre, en la que se debe verbalizar el contenido de la mente sin filtro voluntario alguno. Recuerda también a lo dicho por Bion (1982) acerca de entregarse al análisis "sin memoria ni deseo", palabras que, aunque aplicadas al analista, sirven también para transitar los retorcidos caminos del inconsciente en primera persona.

En efecto, es un viaje que requiere ceder control, pues la verdad se encuentra en las sombras que arroja la luz de la razón. Se debe viajar sin armas, despojándose tanto de las de la consciencia como de aquellas que se portan de forma involuntaria. Hablamos, en este último caso, de las defensas, "operaciones cuya finalidad consiste en reducir o suprimir toda modificación susceptible de poner en peligro la integridad y la constancia del individuo" (Laplanche y Pontalis, 2016, p. 113).

También sin juicio valorativo, sin diferenciar lo bueno de lo malo, lo bello de lo feo, pues es precisamente en lo rechazado, en eso que se halla fuera de la ley del individuo, donde podemos encontrar los primeros retazos de las verdades que nos conducirán mucho más allá. No en vano aprendemos entonces que "Atreyu" significa "hijo de todos" (Ende, 1989, p. 45); se trata quizá de una representación del cazador que se haya dentro de cada una de las personas que deciden emprender la búsqueda de la respuesta a la enfermedad sin nombre de un mundo. El camino de Atreyu es el de Bastián, y es, también, el nuestro.
La búsqueda de la cura para su Emperatriz le conduce hasta las puertas del Oráculo del Sur, protegidas por dos esfinges guardianas que, como en la Tebas de Edipo, custodian celosamente la verdad:

(...) su rostro era el de un ser humano...por lo menos en cuanto a la forma, porque su expresión no era humana. Era difícil saber si aquel rostro sonreía, o reflejaba una tristeza inmensa o una indiferencia total. A Atreyu, después de contemplarlo durante un rato, le pareció lleno de maldad y de una crueldad abismales, pero en seguida tuvo que corregir su impresión al no encontrar en él más que serenidad (Ende, 1989, p. 82).

Figuras relacionadas con lo humano y que pese a ello -o por ello- resultan tan ajenas al individuo que podemos entender que guardan verdades que quizá sea mejor no conocer, aquellas que deben ocultarse de la luz de la razón porque amenazan los fundamentos mismos de la persona que creemos ser. Es precisamente el espacio que hay entre ambas esfinges lo que constituye la Puerta del Gran Enigma: una puerta que carece de batientes, pero que nadie puede cruzar salvo si sus guardianas cierran los ojos. En el caso contrario permanecerá infranqueable, pues sus ojos transmiten "todos los enigmas del mundo" (Ende, 1989, p. 88), y por tanto dejan paralizados a quienes caen bajo su mirada; al menos, hasta que puedan resolverlos todos. Su mirada sólo puede ser resistida por la de otra esfinge, y por ello se miran a los ojos eternamente.

Como Atreyu descubre, no hay ningún criterio comprensible por el que las esfinges dejen pasar a unas personas y a otras no: no es su valor, ni su bondad, ni su belleza las cualidades que respetan las criaturas. Ante la pregunta de cómo pasar entre ellas, no hay consejo posible: "Debes hacer lo que tengas que hacer (...). Esperar a que ellas decidan...sin saber por qué" (Ende, 1989, p. 88).

Entregarse a un viaje sin retorno hacia la verdad, sin memoria ni deseo, sin garantía alguna del resultado. Esa es la primera prueba -aprende Bastián a través de Atreyu, y nosotros con él- a afrontar en el camino hacia el autoconocimiento que supone la individuación, hacia afrontar lo rechazado y nombrar lo innombrable, y hacia la conquista de la integración psíquica. Todo ello a pesar de la angustia que nos protege de lo que no nos atrevemos a saber:

Atreyu tuvo miedo. No era tanto miedo al peligro que lo amenazaba; era un miedo que procedía de sí mismo. (...) era el miedo a lo incomprensible, a lo desmesuradamente grandioso, a la realidad de lo prepotente lo que hacía sus piernas cada vez más pesadas, hasta que le pareció tenerlas de plomo frío y gris. Sin embargo, siguió adelante (Ende, 1989. p. 95). 
Poco después de aprender sobre la Puerta del Gran Enigma, Atreyu -y Bastián a través de él- conoce la Puerta del Espejo Mágico. Resulta interesante señalar que, al tiempo que lee la aventura de Atreyu, en ese punto descubre el espejo del desván en el que se encuentra:

Entonces Bastián se asustó, porque en un rincón oscuro se agitaba algo (...) un gran espejo de medio cuerpo, en el que se había visto borrosamente reflejado a sí mismo. (...) Realmente, no resultaba muy guapo con aquel cuerpo gordo, las piernas torcidas, y la cara pálida. Movió la cabeza lentamente y dijo en voz alta:

$$
\text { -iNo! (Ende, 1989, p. 92). }
$$

Es entonces cuando se desvela el misterio de la Puerta del Espejo Mágico, tan sencillo como atroz:

(...) cuando se está ante él, se ve uno a sí mismo... pero no como en un espejo corriente, desde luego. No se ve el exterior, sino el verdadero interior de uno, tal y como en realidad es. Quien quiera atravesarlo tiene que (...) penetrar en sí mismo. (...) los visitantes que se consideran especialmente intachables huyen gritando del monstruo que los mira irónicamente desde el espejo (Ende, 1989, p. 92).

Si tenemos en cuenta que el proceso de individuación puede resumirse como la integración de los aspectos que negamos de nosotros mismos, este espejo particular representa su primer guardián: la sombra.

La sombra es el arquetipo del enemigo (Stevens, 1993. p. 55.), todo lo que es rechazado por tratarse de aspectos demasiados crueles, animales o bárbaros de nosotros mismos. Es el eco bestial en los humanos que es negado por la luz de la razón y, precisamente por ello, por estar oculto y rechazado, muestra un aspecto más oscuro al de cualquier animal; después de todo, lo inhumano nunca fue tan terrible como lo humano.

Tal y como nos indica Stevens, reconocer nuestra sombra es una experiencia "potencialmente aterradora", y por eso es común que se deposite en los otros mediante el mecanismo de proyección (1993, p. 55). Este conjunto de aspectos bestiales está alejado de la lógica de la civilización y por tanto, tanto individual como colectivamente, se deposita en el otro. Pero por eso es precisamente la puerta al proceso de individuación, aceptar lo inaceptable que hay en nosotros, ya que "sólo cuando me acepto a mí mismo puedo cambiar" (Rogers, 1961). Como en el proceso de individuación, quienes han podido cruzar la Puerta "tuvieron que vencerse a sí mismos. No se puede decir nada que valga para todos los casos. Para cada uno es diferente" (Ende, 1989, p. 93).
$Y$ ya podemos intuir con qué se encuentra Atreyu cuando mira en el interior del Espejo:

(...) en lugar de una imagen aterradora vio algo con lo que no había contado en absoluto y que tampoco pudo comprender. Vio a un muchacho gordo y de pálido rostro (...) que, con las piernas cruzadas, se sentaba en un lecho de colchonetas y leía un libro (Ende, 1989, p. 98).

En efecto, Atreyu atraviesa la imagen de Bastián, su opuesto, un muchacho miedoso que carece de las cualidades de las que él goza: fuerza y valor. Pero tal vez, como la luz y la sombra, ambos no son tan opuestos estancos como son contrarios en relación: polos de una misma unidad tan contraria como indivisible.

La última barrera antes de que Atreyu pueda encontrar al Oráculo del Sur se trata de la Puerta Sin Llave: "Cuanto más se quiere entrar, tanto más se cierra la puerta. Pero cuando alguien logra olvidar sus intenciones y no querer nada... La puerta se abre sola ante él" (Ende, 1989, p. 93).

Existe un fuerte paralelismo entre esta última puerta y el proceso de autoconocimiento para integrar los aspectos negados del individuo. No se trata de renunciar a las dinámicas del deseo, como podría pensarse en un primer momento, ya que en todo el relato que compone La Historia Interminable, los deseos genuinos y en muchos casos irracionales devienen el motor del mundo de Fantasía y son, como veremos más adelante, su única posibilidad de salvación. Muy al contrario, el fragmento señalado se refiere al deseo consciente que nosotros podríamos traducir como "voluntad racional", una capacidad sumamente útil en el desenvolvimiento de las personas en la vida cotidiana pero que tanto obstaculiza la exploración del inconsciente, ya que "es necesario prescindir de la actitud utilitaria de los proyectos conscientes con el fin de dejar paso al desarrollo interno de la personalidad" (Franz, 1995, p. 163). Como ya nos hizo sospechar Freud (2002), la voluntad consciente no es la certera luz de la razón ni es tan libre como pensamos, sino que está determinada por lo inconsciente y las defensas apuntaladas para evitar su exploración. En su lugar, dejarse arrastrar por la inercia de la subjetividad, de lo aparentemente absurdo o azaroso -como en la asociación libre-, o seguir determinado impulso inexplicable -aquí encontraríamos la tesis ya mencionada de Jung del sí mismo como guía interno- puede ser la respuesta adecuada.

Tras producirse la aceptación de la sombra -que en este caso quiere decir que Atreyu atraviese el mismo espejo en el que ve a Bastián-, y el compromiso con lo que de inexplicable hay en uno mismo -al "olvidar sus intenciones" para abrir la última Puerta-, el proceso continúa. 
Seguimos la línea de la narración y lo que hay detrás de ella al entramado profundo de la individuación: "El sonido se acercó: era una voz que cantaba, muy bella y argentina y alta como la de un niño, pero que sonaba infinitamente triste e incluso parecía a veces sollozar" (Ende, 1989, p. 103).

El Oráculo del Sur, quien tiene todas las respuestas, no se trata de una sabia vidente ni de un anciano erudito, sino de la voz sin cuerpo de un niño triste. Quizá sea la misma voz que en cierto momento renunciamos a escuchar y tuvimos que encerrar tras puertas casi infranqueables. Una voz que, precisamente por hablar de la verdad, permanece siempre pospuesta, relegada a rincones ocultos de la psique: "Nunca ha ocurrido / que nadie me viera. / Soy un latido / siempre a la espera" (Ende, 1989, p. 104).

Incluso tras haber llegado Atreyu al lugar donde al fin puede escuchar la voz tenue del Oráculo, éste sólo puede comunicarse de forma indirecta, enigmática, y en verso. No de manera diferente a cómo se expresa lo inconsciente: mediante asociaciones "inexplicables", sueños, lapsus, síntomas.

El simple contacto con ello de forma descarnada cambia algo en las personas, puesto que ya no pueden sustentar la imagen que hasta en ese momento tenían de sí. La identidad sufre, precisamente porque se ve asaltada por aspectos de la psique que habían quedado fuera de ella. No sólo la máscara que nos ponemos bajo un criterio de adaptación se desvela precaria -el arquetipo de la persona- (Stevens, 1993, p. 54), sino que todo lo que creíamos racional de nosotros mismos, lo que se encuentra iluminado por la luz de la consciencia, se tambalea.

Entendemos que esto es lo que siente Atreyu tras el enfrentamiento con su sombra cuando el oráculo le pregunta quién es: "-¿Quién soy? -murmuró-. No podría decirlo. Me parece que alguna vez sí lo he sabido. Pero, ¿es tan importante?" (Ende, 1989, p. 103).

Los destellos de intuición de ese tipo pueden ser breves, pero, como vemos, lo suficientemente poderosos como para cambiarlo todo. Atreyu, y Bastián, y nosotros como "meta-lectores", enfrentamos y enfrentaremos, en algún momento, la revelación de que no somos quienes creíamos ser y, al tiempo, de que somos quien no creíamos ser. La creencia de la identidad personal es importante, incluso fundamental. Al fin de al cabo, sin ello nos enfrentaríamos directamente a la angustia psicótica de la disolución. Sin embargo, no resulta tan importante como lo que queda fuera de ella, precisamente porque es esto lo que conforma el terreno del análisis, el sendero retorcido proceso de individuación, y el campo de juego de la integración psíquica.

Atreyu sale de los dominios del Oráculo con la respuesta a su pregunta: la Emperatriz necesita un nom- bre, y por eso se muere, pero nadie dentro de Fantasía puede dárselo. Derrotado, vuelve con su soberana para anunciarle el fracaso de su aventura, pero ella le anuncia que sí hay una persona capaz de darle su nombre, pero no existe dentro de Fantasía: "Entraste en su imagen y la llevaste contigo" (Ende, 1989, p. 163).

De nuevo, encontramos el indicio, apuntado en la narrativa y teorizado sistemáticamente por el psicoanálisis, de que la capacidad para nombrar lo innominado requiere de aceptar lo negado y llevarlo con nosotros.

Recordemos ahora que la Emperatriz es soberana de un mundo sin fronteras, la niña más vieja que todos los demás seres, una figura sin edad. Su símbolo son dos serpientes, una blanca y una negra, devorándose en un doble ouroboros, símbolo del renacimiento y la unidad de opuestos.

Vemos el trazo paralelo que siguen La Historia Interminable y las teorías jungianas cuando encontramos que tras la acogida de la sombra aparece "otra figura interior" (Franz, 1995, p. 177), la expresión de aquello rechazado de forma más profunda aún que la sombra, y que en líneas generales podríamos definir como aquello asociado con lo masculino en la mujer y aquello asociado con lo femenino en el hombre: el arquetipo del ánimus y el ánima. Hacerse individuo, integrar lo escindido, es precisamente la meta del proceso: integrar ambas partes en la persona para hallar el sí mismo. Esta unidad del par supremo de contrarios es la sicigia "que da la promesa de unión y la hace realmente posible" (Stevens, 1993, p. 58).

Aunque los estereotipos y las normas político-culturales en torno al género eran más rígidas en la época en la que Jung escribe que en nuestros días, resulta importante tener en cuenta que tales diferencias siguen existiendo hoy en día, si bien de forma diferente, y que contravenir tales normas de separación deja una huella en los individuos.

Precisamente por su carácter oculto y rechazado, el ánima aparece como mediadora entre el yo y el sí mismo como dimensión de totalidad individual: sin ella, no habrá unicidad, habrá algo fundamental siempre separado de la experiencia. El papel del ánima como guía de la experiencia se encuentra plasmado en diversas obras culturales, entre las que podemos citar a la Beatriz de La Divina Comedia (Franz, 1995, p. 185).

Tras el atravesamiento de la sombra podemos comprender que la Emperatriz necesita un nombre, y lo mismo hace Bastián. En ese momento entiende que, si bien hasta ahora ha sido espectador pasivo del proceso, ahora debe tomar la responsabilidad en primera persona, y darle su nombre: Hija de la Luna.

El nombre no carece de importancia, pero lo descubrimos algo más tarde, cuando Bastián ya ha sido 
transformado en uno de los personajes de la misma novela que estaba leyendo y ha pasado de ser pasivo a activo, de paciente a agente del cambio. Es entonces cuando se le revela que el reino de Fantasía sólo podrá recuperarse del ataque devastador de la Nada gracias a sus deseos.

Como ya hemos citado previamente, la Emperatriz indica: "Fantasía nacerá de nuevo a través de tus deseos, Bastián, que se harán realidad a través de mí". Para ello deberá ir solo, pero llevando siempre el símbolo de ella, el doble ouroborus ya mencionado, que en su parte posterior reza: Haz lo que quieras.

Es de relevancia mencionar que Hija de la Luna es el título de uno de los libros escritos por el conocido ocultista británico Aleister Crowley en 1917 (publicado en 1929). Crowley es uno de los representantes más conocidos de la filosofía de la Thelema, cuyos principios rectores más conocidos son "Haz tu voluntad, ésa es toda ley" y "Amor es ley, amor bajo la voluntad" (Booth, 2001). Podemos encontrar este primer principio sintetizado entre las páginas de nuestro libro:

-¿Qué significa -preguntó- "HAZ LO QUE QUIERAS»? Eso quiere decir que puedo hacer lo que me dé la gana, ¿no crees?

-(...) Quiere decir que debes hacer tu Verdadera Voluntad. Y no hay nada más difícil.(...) Es tu secreto más profundo, que no conoces.

\section{-¿Cómo puedo descubrirlo entonces?}

-Siguiendo el camino de los deseos, uno a uno, hasta llegar al último. Este camino te conducirá a tu verdadera voluntad. (...) exige la mayor autenticidad y atención, porque en ningún otro es tan fácil perderse para siempre (Ende, 1989, p. 217).

Aquí vemos un correlato importante respecto al proceso de autoconocimiento e integración psíquica hasta devenir "individuo". Este también es un camino largo, que requiere de la dinámica del deseo como motor de lo inconsciente, pero en el que hay que distinguir la voluntad verdadera de todo lo demás que se hace pasar por ella: el beneficio del síntoma, los mecanismos de defensa, el enrocamiento de la resistencia... El secreto mejor guardado, el núcleo del sí mismo, de lo que verdaderamente somos sin las grietas de aqueIlo que nos ha escindido durante nuestro desarrollo, es la meta de ese camino.

Un camino que nunca es recto, como aprende Bastián en su larga andadura, cuando se lamenta de todos los rodeos que acaba dando para no conseguir nada:

-Lo hice todo mal -dijo- y lo entendí todo al revés. La Hija de la Luna me dio muchas cosas pero, con ellas, sólo traje la desgracia sobre mí y sobre Fantasía.
(...)

-No -respondió-, eso no lo creo. Seguiste el camino de los deseos y ese camino nunca es derecho. Diste un gran rodeo, pero era tu camino. ¿Y sabes por qué? Tú eres uno de esos que sólo pueden regresar cuando encuentran la fuente de donde brota el Agua de la Vida. Y ése es el lugar más secreto de toda Fantasía. (...) Cualquier camino que conduzca allí es en definitiva el verdadero" (Ende, 1989, p. 369).

Pero que no sea recto no quiere decir que no sea correcto, pues si después de recorrer varios caminos Bastián no está un paso más cerca de su verdadera voluntad, del último deseo, en realidad ha ganado comprensión, sabe ya los caminos que no debe recorrer:

La Casa del Cambio no se llama sólo así porque se cambie a sí misma, sino porque cambia también a quien entra en ella. $Y$ eso era muy importante para el niño [Bastián], que hasta encontrarla siempre había querido ser otro, pero no cambiar (Ende, 1989, p. 364).

Es entonces, tras mostrarnos secuencialmente la necesidad de aceptar lo socialmente rechazado atravesando nuestra sombra, de ceder ante el empuje de lo incomprensible de nosotros, de encontrarnos con lo negado de nuestro interior y darle un nombre, y de seguir la ruta retorcida de nuestro mundo del deseo, cuando se nos muestra que ser "uno mismo" es lo contrario de una identidad estática: significa también cambiar en la dirección adecuada: "-Ahora has encontrado tu último deseo. (...) Tu Verdadera Voluntad es querer" (Ende, 1989, p, 371).

La única oportunidad de Bastián de regresar a su mundo es encontrar a alguien a quien querer en el cementerio de sueños, alguien de su mundo al que llevarle el Agua de la Vida, pues ésa es la manera de hacerse con ella. Una demanda de amor, quizá, como cimiento de todo el largo camino hacia el cambio y la comprensión de uno mismo:

Rápidamente cogió con las dos manos agua de las Aguas de la Vida y corrió hacia la puerta (...).

-¡Papá! -gritó-. ¡Papá! ¡Soy...Bastián...Baltasar... Bux! (Ende, 1989, p. 392).

Aunque el Agua de la Vida se derrama en el último momento, Bastián es capaz de volver a la realidad, alejarse del mundo sin fronteras de su Fantasía, habiendo aceptado lo negado de sí, sabiendo quién es. El cambio de uno mismo es sutil, pero profundo. Radical, pese a muchas veces no ser espectacular. Cambias sin cambiar quién eres, porque quizá lo único diferente es la dirección en la que se cambia. 
Poder apartar una sombra. Poder encontrar en un padre pétreo y distante alguien a quien abrazar:

"El padre se sentaba inmóvil. Bastán se puso en pie y encendió la luz. Y entonces vio algo que jamás había visto antes. Vio lágrimas en los ojos de su padre. Y comprendió que, a pesar de todo, había podido traerle el Agua de la Vida" (Ende, 1989, p. 395).

\section{CONCLUSIONES}

La clave de bóveda de este trabajo ha sido la relación entre arte y psicoanálisis, y su meta principal arrojar luz sobre la cuestión de cómo dicha relación no es únicamente unidireccional, en el sentido de aplicar los postulados del psicoanálisis a la creación artística -en este caso, literaria- para el entendimiento de las dinámicas psíquicas que la subyacen sino, precisamente, invertir el sentido de esta conexión y aplicar el arte al psicoanálisis. Es éste carácter de avanzada de la obra literaria en la intuición de vida anímica y en relación con las sistematizaciones teóricas posteriores o paralelas, lo que Jacques Lacan identificó como "el artista precede", y Carl Gustav Jung denominó "arte visionario".

En lo concreto, hemos encontrado que La Historia Interminable, novela de fantasía publicada por Michael Ende en 1979, traza las líneas básicas de importantes postulados de estos dos autores. El doble viaje iniciático que propone la novela, es decir, el de Atreyu y el de Bastián, muestra la importancia estructural de la trama simbólico-imaginaria. En primer lugar, y recorriendo toda la obra literaria como su espina dorsal, encontramos que es la dinámica del verdadero deseo el motor principal de los seres humanos, subvirtiendo la lógica general, imaginaria, por la cual somos artífices conscientes de nuestros cambios, iluminados siempre por la luz de la razón y la voluntad. Como le ocurre también a Bastián, son nuestros deseos irracionales y espontáneos los que nos llevan lejos de casa, y de igual modo los que nos muestran el camino de vuelta.

También nos hemos topado por la importancia crucial de lo simbólico. Tanto para el apuntalamiento de las ilusiones de la dimensión imaginaria -como ya ha sido mencionado, las ediciones del libro tienen tinta de dos colores-, como para la estructuración general de la vida anímica: la necesidad de mantener un nombre en la Torre de Marfil para mantener viva Fantasía. La Emperatriz Infantil nos enseña que lo que permanece innominado enferma y hace enfermar nuestro mundo, y la gesta por encontrarle un nombre, por muy provisional que sea, es lo único que puede salvarnos de la angustia de la disolución. La Nada que ciega y devora, un correlato imperfecto, pero claro, de la dimensión anuladora de lo Real.

Asimismo, hemos tratado de exponer cómo $L a$ Historia Interminable traza el sendero del proceso de individuación teorizado por C. G. Jung, incluyendo el contacto con los arquetipos del inconsciente colectivo. El objetivo de este proceso -con sus evidentes diferencias en lo concreto- es común a todos los objetivos de curación o integración psíquica de las diferentes corrientes psicoanalíticas: aceptar lo rechazado, unir lo que de escindido hay en los individuos. Es precisamente por eso que la meta de la individuación es hallar el sí-mismo, entendiendo esto no cómo un concepto estático, sino, precisamente, como la necesidad de cambiar en la dirección correcta.

Para ello necesitamos la decisión, no voluntaria ni racional en última instancia, de entregarnos a una búsqueda que no sabemos dónde llevará, de ceder ante un empuje implícito, lo compartido tanto por Atreyu al atravesar la Puerta del Gran Enigma como por la persona que, asumiendo el papel de analizando, acepta la ayuda para explorar los significados ocultos de su inconsciente. Como aprende también Bastián, los caminos verdaderos son muchas veces retorcidos.

$Y$ uno de los pasos fundamentales en este camino es enfrentar la propia sombra que arroja la luz de nuestra razón, no para vencerla ni para anularla, sino para atravesarla. Aceptar lo que de socialmente aberrante hay en nosotros mismos y que ha sido relegado a partes más oscuras de nuestra psique. Uno de los ejemplos más comunes en la línea jungiana es lo monstruoso, lo bestial, o lo incivilizado, pero no hemos de olvidar que ver en el espejo al Bastián que hay en todo Atreyu, el temor que late en toda valentía, es un proceso igualmente necesario para el autoconocimiento.

Sin embargo, esto dista mucho de ser el final. Hay partes más escindidas, divisiones más profundas, relacionadas con la diferenciación de género y lo que se asocia a ella. Aunque resulta evidente que existe una diferenciación biológica básica, tanto anatomía como genética son palabras que hemos dado a algo externo, real, que excede nuestra consciencia, y precisamente su percepción implica un tamiz del que no estamos exentos, y quizá la única herramienta sea ser conscientes (o lo más conscientes posible) de ello. Porque el pasado vive de algún modo en el presente, y esto no se refiere sólo a la historia estrictamente individual, sino también a la social y cultural.

Por ello, los elementos más profundos de nuestra psique, vida anímica abisal radicalmente diferente a lo que nada en nuestra superficie, lo que los jungianos llamaron ánima y ánimus, merece ser reconocido y aceptado: un nombre para nuestra Emperatriz Infantil.

Este paso fundamental hacia la unicidad es necesario para encontrar, como consigue Bastián, la verdadera voluntad, el deseo más profundo que nuclea lo que somos y en base al cual podemos ser nosotros mismos, es decir, cambiar en la dirección adecuada. Y el deseo tiene un objeto, es la forma particular de relación en la cual se estructura nuestra vida psíquica, pues lo ob- 
jetal es lo único que genera vida en el significado más amplio del término.

Como aprende Bastián al final de su Historia Interminable, el Agua de la Vida sólo puede obtenerse si es para dársela a otro.

\section{AGRADECIMIENTOS}

Este trabajo ha sido realizado en el marco del Proyecto de Investigación RTI2018-098006-B-100 (MINCIU/FEDER)

\section{BIBLIOGRAFÍA}

Bion, Wilfred Ruprecht (1982), La tabla y la cesura. Bion en Nueva York y San Pablo, Buenos Aires, Paidós.

Boccarius, Peter (1990), Michael Ende: der Anfang der Geschichte, Múnich, Nymphenburger.

Booth, Martin (2001), A Magic Life. A biography of Aleister Crowley, Londres, Hodder and Stoughton.

Campbell, Joseph (2013), El héroe de las mil caras. Psicoanálisis del mito, México DF, Fondo de Cultura Económica. (Trabajo original publicado en 1949).

Crowley, Aleister (1929), Moonchild, Londres, Mandrake Press.

Ende, Michael (1989), La Historia Interminable, Sant Vincenç dels Horts, Círculo de Lectores.

Freud, Sigmund (1973), "Historia del Movimiento Psicoanalítico". En: Obras Completas (vol. II), Madrid, Biblioteca Nueva. (Trabajo original publicado en 1914).

Freud, Sigmund (2002), La interpretación de los sueños, Madrid, Biblioteca Nueva. (Trabajo original publicado en 1899).

Hillman, James, (2004), El sueño y el inframundo. Barcelona, Paidós Ibérica.

Hocke, Roman y Kraft, Thomas (1997), Michael Ende und seine phantastische Welt, Stuttgart/Viena/Berna, Weitbrecht-Verlag/K. Thienmanns Verlag.

Jiménez Ariza, María del Carmen (2013), "Sobre mitos antiguos y héroes modernos: Una relectura de La Historia Interminable a partir de El héroe de las mil caras", Revista Álabe 8, pp. 1-20.
Jung, Carl Gustav (1970), Arquetipos e inconsciente colectivo. Barcelona, Paidós Ibérica.

Lacan, Jacques (1986), Seminario 2: El yo en la teoría de Freud y en la técnica psicoanalítica. Barcelona, Paidós.

Lacan, Jacques (1988), Intervenciones y textos 2, Buenos Aires, Manantial, p. 66.

Lacan, Jacques (1990), La ética del psicoanálisis. Seminario, Buenos Aires, Paidós.

Laín Entralgo, Pedro (2005), La curación por la palabra en la Antigüedad clásica, Barcelona, Anthropos. (Trabajo original publicado en 1958).

Laplanche, Jean; Pontalis, Jean-Bertrand (2016), Diccionario de psicoanálisis, Barcelona, Paidós.

Marinas, José Miguel (2004), Kant y el reverso de la ilustración: una lectura ética y política de Lacan, Revista de Filosofía, 33 pp. 119-134.

Montiel, Luis (1997), Jung. Madrid, Ediciones del Orto.

Montiel, Luis (2012), El rizoma oculto de la psicología profunda. Gustav Meyrink y Carl Gustav Jung, Madrid, Frenia.

Nietzsche, F. (1970). "La genealogía de la moral". En: Obras completas (Vol. III), Buenos Aires, Prestigio. (Trabajo original publicado en 1887).

Regnault, François (1995), El Arte según Lacan y otras conferencias, Barcelona, Ediciones Eolia.

Rogers, Carl (1961), El proceso de convertirse en persona: mi técnica terapéutica, Buenos Aires, Paidós.

Sánchez, Blanca (2015), "Lacan y la literatura: algo más que un gesto de cortesía", Revista Conclusiones Analíticas, 2 (2), pp. 123-139.

Stevens, Anthony (1993), Jung o la búsqueda de la identidad. Madrid, Editorial Debate.

Tolkien, John Ronald Reuel (2002), El Hobbit. Historia de una ida y una vuelta, Barcelona, Minotauro. (Trabajo original publicado en 1937).

Von Franz, Marie-Louise (1995), "El proceso de individuación". En: Jung, Carl Gustav (ed.), El hombre y sus símbolos, Barcelona, Paidós Ibérica, (pp. 158-329). (Trabajo original publicado en 1964). 